(n)

\title{
Incidence, prevalence and seasonal onset variation of Addison's disease among persons with type 1 diabetes mellitus: nationwide, matched cohort studies
}

\author{
Dimitrios Chantzichristos ${ }^{1,2}$, Anders Persson ${ }^{3}$, Björn Eliasson ${ }^{1,2,3}$, Mervete Miftaraj ${ }^{3}$, \\ Stefan Franzén ${ }^{3}$, Ann-Marie Svensson ${ }^{3}$ and Gudmundur Johannsson ${ }^{1,2}$ \\ ${ }^{1}$ Department of Internal Medicine and Clinical Nutrition, Institute of Medicine at Sahlgrenska Academy, University \\ of Gothenburg, Gothenburg, Sweden, ${ }^{2}$ Department of Endocrinology-Diabetes-Metabolism, Sahlgrenska University \\ Hospital, Gothenburg, Sweden, and ${ }^{3}$ Department of Medicine, National Diabetes Register, Centre of Registers, \\ University of Gothenburg, Gothenburg, Sweden
}

\author{
Correspondence \\ should be addressed \\ to $D$ Chantzichristos \\ Email \\ dimitrios.chantzichristos@ \\ gu.se
}

\begin{abstract}
Objectives: We determined the incidence and prevalence of Addison's disease (AD) among persons with or without type 1 diabetes mellitus (T1DM) in nationwide, matched cohort studies.

Methods: Persons with T1DM were identified from the Swedish National Diabetes Register and each was matched for age, sex, year and county to five controls randomly selected from the general population. Persons with AD were identified from the Swedish National Inpatient Register. Baseline demographics and seasonal onset variation of AD were presented by descriptive statistics. Prevalence and incidence were estimated by proportions and incidence rates, respectively. Times to AD were analyzed using the Cox proportional hazard model.

Results: Between 1998 and 2013, 66 persons with T1DM were diagnosed with AD at a mean age (s.D.) of 36.4 (13.0) years among 36514 persons with T1DM, while 32 were diagnosed with AD at a mean age of 42.7 (15.2) years among 182570 controls. The difference in mean age at diagnosis of AD between the groups was 6.3 years $(P$ value $=0.036)$. The incidence of AD for a person with or without T1DM was therefore 193 and 18 per million person-years, respectively. The adjusted relative risk increase of developing AD in T1DM was 10.8 (95\% Cl: 7.1-16.5). The highest incidence of AD was observed during February-March and September-October. The prevalence of AD in persons with or without T1DM in December 2012 was 3410 and 208 per million, respectively. The odds ratio for AD in persons with T1DM vs controls was 16.5 (95\% Cl: 11.1-24.5).

Conclusion: The risk to develop AD among persons with T1DM is more than 10 times higher than in persons without T1DM. Persons with T1DM develop AD at a younger age. The incidence of AD may have a seasonal pattern.
\end{abstract}

\section{Introduction}

The incidence and prevalence of type 1 diabetes mellitus (T1DM) are increasing globally (1). A person with one autoimmune disorder, such as T1DM, is at an increased risk of developing another autoimmune disease, such as primary adrenal insufficiency or Addison's disease (AD).
The frequency of additional autoimmune diseases in T1DM shows an age-dependent increase (2). At present, there is no consensus whether to perform regular screening for other autoimmune diseases among persons with T1DM as the magnitude of risk is poorly known. Persons with www.eje-online.org

https://doi.org/10.1530/EJE-17-0751
() 2018 European Society of Endocrinology Printed in Great Britain
European Journal of

Endocrinology

(2018) 178, 113-120 
either T1DM and/or autoimmune thyroid disease and $\mathrm{AD}$ are classified as having autoimmune polyendocrine syndrome type 2 (3). Persons with autoimmune thyroid disease have an at least 10 times higher risk of developing other autoimmune diseases, e.g., pernicious anemia, systemic lupus erythematosus, AD and celiac disease (4).

Both the incidence and the prevalence of $\mathrm{AD}$ are probably increasing in persons with T1DM (5). The prevalence of $\mathrm{AD}$ in different European populations varies between 93 and 221 per million and has an estimated incidence of 4.4-6.2 per million per year (Table 1) $(6,7$, $8,9,10,11,12)$. Women are more frequently affected than men and age at diagnosis peaks in the fourth decade of life $(6,7,8,9)$. For T1DM, there are studies reporting a seasonal variation in its diagnosis (winter peaks and summer troughs), which may be explained by the seasonal variation of infectious diseases $(13,14)$. There is, however, no such data for persons with AD where it could be speculated that seasons with a high burden of infections might provoke an adrenal crisis in persons with undiagnosed disease.

Having both T1DM and $\mathrm{AD}$ is rare $(10,15)$, and we have recently shown that this combination of endocrine metabolic diseases is associated with an excess mortality that markedly exceeds the mortality for T1DM and $\mathrm{AD}$ per se (16). Between $10.7 \%$ and $12 \%$ of persons with $\mathrm{AD}$ also have T1DM $(10,17)$ and the estimated prevalence of the combination in Western Norway was 20 per million persons in the population (9), whereas in a US population of persons with T1DM, it was found to be 2912 per million (2). The incidence and prevalence of this rare combination of metabolic diseases are therefore not fully characterized. The primary aim of our studies was to estimate the incidence of $\mathrm{AD}$ in persons with or without T1DM. Secondary aims were to study the prevalence of the combination of T1DM and $\mathrm{AD}$ and the possible impact of season on the incidence of AD.

\section{Subjects and methods}

\section{Study design}

We conducted two separate nationwide, matched, observational cohort studies (one for the incidence during 1998-2013 and one for the prevalence at December 2012) retrieving data from the Swedish National Diabetes Register (NDR), the Swedish National Inpatient Register and the Swedish Longitudinal Integration Database for Health Insurance and Labor Market Studies. NDR is a quality register with at least $97 \%$ nationwide coverage (18) in which detailed clinical information (medications, risk factors and diabetic complications) in adult persons with T1DM is reported. Each person provides informed consent for inclusion in the register. The Swedish National Inpatient Register includes data on all inpatient admissions in Sweden from 1987 onward, is mandatory for all physicians (private and publicly funded), has a complete national coverage, is continuously validated and is linked to other registries by a unique personal identification code $(19,20)$. The Swedish Longitudinal Integration Database for Health Insurance and Labor Market Studies includes information on education level, income, civil status and county for all individuals older than 16 years of age registered in Sweden from 1990 onward (21).

The studies were approved by the Regional Ethical Review Board in Gothenburg, Sweden (diary numbers 563-12 and 776-14). The research complied with the Declaration of Helsinki.

\section{Procedures}

To study the incidence of $\mathrm{AD}$ among persons with or without T1DM, we conducted a cohort study where the outcome was AD. First, we identified all persons with T1DM registered in the NDR from 1 January 1998 onward

Table 1 Incidence and prevalence of $A D$ in Europe.

\begin{tabular}{ll}
\hline Reference & Location \\
\hline (6) & Nottingham, UK \\
$(7)$ & Coventry, UK \\
$(8)$ & Umbria, Italy \\
$(9)$ & Western Norway \\
$(10)^{*}$ & Norway \\
$(11)$ & Sweden \\
$(12)$ & Iceland \\
\hline
\end{tabular}

\begin{tabular}{l}
$\begin{array}{l}\text { No. of cases with AD and } \\
\text { size of study population }\end{array}$ \\
\hline 66 of 600000 \\
30 of 323852 \\
95 of 811887 \\
128 of 916000 \\
664 of 4603263 \\
1305 cases with AD \\
53 of 239724 \\
\hline
\end{tabular}

\begin{tabular}{c}
\hline $\begin{array}{c}\text { Incidence of AD per million } \\
\text { person-years }\end{array}$ \\
\hline 5.6 \\
- \\
- \\
6.2 \\
4.4 \\
6.0 \\
- \\
\hline
\end{tabular}

\begin{tabular}{c}
$\begin{array}{c}\text { Prevalence of AD per } \\
\text { million }\end{array}$ \\
\hline 110 \\
93 \\
$117(95-143)^{\dagger}$ \\
140 \\
144 \\
131 \\
221
\end{tabular}

${ }^{\dagger} 95 \% \mathrm{Cl}$ presented where available; *The prevalence of both AD and T1DM (49 among 426 persons with AD) was 20 per million persons. $A D$, Addison's disease; $\mathrm{Cl}$, confidence interval. 


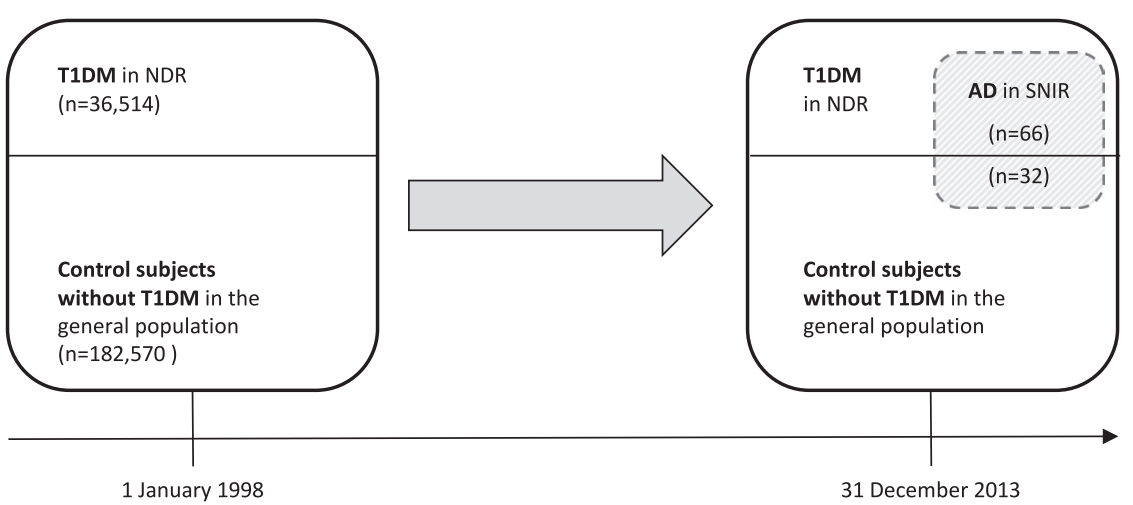

\section{Figure 1}

Schematic of the design for the incidence study of $A D$ among persons with or without T1DM. Cases with T1DM were identified in the NDR and matched control subjects without T1DM were identified in the general population from 1 January 1998 and onward. Both groups were followed until 31 December 2013. A total of 98 new cases of AD were identified in the SNIR. AD, Addison's disease; NDR, National Diabetes Register; SNIR, Swedish National Inpatient Register; T1DM, type 1 diabetes mellitus.
(Fig. 1). Contemporaneously with the first registration for each person with T1DM in the NDR (baseline), five control subjects randomly selected from the general population without T1DM were identified matched for age, gender, calendar year and county. We then identified subjects within these groups with AD in the Swedish National Inpatient Register until 31 December 2013. All persons with an AD diagnosis preceding the T1DM diagnosis were excluded and all persons deceased before 31 December 2013 were censored. Finally, the incidence of AD in the whole study population for each calendar month for the entire observation period was accessed.

For the prevalence of the combination of T1DM and $\mathrm{AD}$, we conducted a cohort study in persons with or without T1DM. We first identified all persons with T1DM alive on 31 December 2012 and then studied backward in time (until 1 January 1987) if they were diagnosed or not with $\mathrm{AD}$ in the Swedish National Inpatient Register. Contemporaneously with the first registration for each person with T1DM in the NDR, five control subjects were randomly selected from the general population without T1DM and were matched for age, gender, calendar year and county.

In all analyses, persons were identified using the codes of the International Classification of Diseases, Ninth Revision (ICD-9) for years 1987-1996 and for ICD-10 for years 1997-2012. The codes used to identify persons with $\mathrm{AD}$ in the Swedish National Inpatient Register were ICD-9 code 255.4 and ICD-10 codes E27.1 and/or E27.2. Our search criteria for AD in the Swedish National Inpatient Register have been previously validated and showed to have a diagnostic performance of 94\% (22). Persons with endogenous Cushing's syndrome and/or any disorders of the pituitary gland were excluded. Details on all ICD-9 and ICD-10 codes used in this study are presented in previous article by our group (16). For T1DM, we used the clinical classification which is the diagnosis attributed to the persons by the physicians who reported them to the NDR. Education level was categorized as low (compulsory only, less than 9 years), middle (10-12 years) or high (university level or similar); civil status was categorized as single, married, divorced or widowed. Annual disposable income was calculated as total personal income minus personal current taxes.

\section{Statistical analysis}

Baseline was defined as the first registration for each person with T1DM in the NDR and the time when the five matched control subjects (without T1DM) randomly selected from the general population were identified. Baseline characteristics and demographics for the incidence cohorts are presented by descriptive statistics, as appropriate. Since no NDR data were available for the matched control subjects, group comparisons based on NDR-specific variables could not be made.

For the incidence of $\mathrm{AD}$ among persons with or without T1DM, the Cox regression analysis was used to model time to AD diagnosis or censoring, with age at baseline and gender as covariates. To study the difference between mean age at $\mathrm{AD}$ diagnosis between the two groups, we used a two-sided independent samples $t$-test, where $P$ value $<0.05$ was considered to be statistically significant. Statistical inference was based on the estimated hazard ratio (95\% confidence interval (CI)) of persons with T1DM compared to their matched control subjects. In addition, time to AD diagnosis was graphically depicted using the Kaplan-Meier method. Evaluation of 
the seasonal variation of the onset of AD was graphically depicted by the number of $\mathrm{AD}$ diagnoses per month (January-December).

The prevalence of $\mathrm{AD}$ in persons with or without T1DM was estimated by their respective proportions. The difference between groups was estimated by the difference in proportions along with the corresponding 95\% CI. In addition, the logistic regression analysis was used to model the probability of AD diagnosis with age at baseline and gender as covariates. Statistical inference was based on the estimated odds ratio (95\% CI) of persons with T1DM compared to their matched control subjects.

\section{Results}

\section{Incidence of $A D$ among persons with or without T1DM}

Between 1998 and 2013, 66 persons (39 men and 27 women) were diagnosed with $\mathrm{AD}$ among 36514 persons with T1DM and 32 (14 men and 18 women) were diagnosed with AD among 182570 control subjects. The demographics for the four different groups are presented in Table 2, showing a male predominance among persons with both T1DM and AD compared to a female predominance of the $\mathrm{AD}$ diagnosis in the general population. Moreover, the mean age (s.D.) when AD was diagnosed was 36.4 (13.0) among persons with T1DM and
42.7 (15.2) among control subjects. The mean difference (95\% CI) between these groups was 6.3 years $(0.43-12.18$, $P$ value $=0.036$ ). Baseline mean HbA1c (s.D.) was 66 (16) $\mathrm{mmol} / \mathrm{mol}$ or $8.2 \%(1.5 \%)$ in persons with T1DM that did not develop AD and 68 (15) $\mathrm{mmol} / \mathrm{mol}$ or $8.4 \%$ (1.4\%) in those that developed AD. For all persons in the incidence cohort, the median time (min-max) in years from inclusion to the end of the study (or death, whichever happened first) was 10.3 years (0.003-16.0).

The time to $\mathrm{AD}$ diagnosis among persons with or without T1DM is shown in Fig. 2 and suggests an earlier development of $\mathrm{AD}$ in persons who already have T1DM.

The incidence of AD among persons with T1DM was 193 per million person-years (95\% CI: 152-245) compared to 18 per million person-years among matched control subjects without T1DM (95\% CI: 13-26) (Table 3). The adjusted relative risk increase (hazard ratio) to develop AD in persons with T1DM was 10.8 times (95\% CI: 7.1-16.5) compared to control subjects without T1DM.

\section{Seasonality of the AD diagnosis}

The cumulative number of new cases with AD diagnosed each calender month during the entire observation period is shown in Fig. 3. This roughly shows a twopeak seasonality for $\mathrm{AD}$ diagnosis in the whole study population: February-March and September-October, which correspond to late and early winter seasons in Sweden, respectively.

Table 2 Baseline demographic and clinical characteristics among persons with T1DM or control subjects and their subgroups with or without AD from the incidence study cohort. Results are presented as $n$ (\%) for categorical variables and mean (S.D.) for continuous variables.

\begin{tabular}{|c|c|c|c|c|}
\hline & T1DM $(n=36448)$ & T1DM + AD $(n=66)$ & Controls $(n=182538)$ & Controls + AD $(n=32)$ \\
\hline Mean (s.D.) age at baseline (years) & $35.2(14.6)$ & $36.4(13.0)^{*}$ & $35.2(14.6)$ & $42.7(15.2) *$ \\
\hline Mean (s.D.) age at T1DM diagnosis (years) & $15.3(7.7)$ & $13.6(7.6)$ & - & - \\
\hline \multicolumn{5}{|l|}{ Sex } \\
\hline Male & $19957(54.8 \%)$ & $39(59.1 \%)$ & $99966(54.8 \%)$ & $14(43.8 \%)$ \\
\hline Female & $16491(45.2 \%)$ & $27(40.9 \%)$ & $82573(45.2 \%)$ & $18(56.2 \%)$ \\
\hline \multicolumn{5}{|l|}{ Educational level } \\
\hline Low & $8091(22.2 \%)$ & $11(16.7 \%)$ & $38681(21.2 \%)$ & $2(6.3 \%)$ \\
\hline Middle & $19294(52.9 \%)$ & $40(60.6 \%)$ & $92429(50.6 \%)$ & $18(56.3 \%)$ \\
\hline High & $8589(23.6 \%)$ & $11(16.7 \%)$ & $48168(26.4 \%)$ & $11(34.4 \%)$ \\
\hline \multicolumn{5}{|l|}{ Civil status } \\
\hline Single & $22558(61.9 \%)$ & $41(62.1 \%)$ & $109543(60.0 \%)$ & $16(50.0 \%)$ \\
\hline Married & $10688(29.3 \%)$ & $17(25.8 \%)$ & $57078(31.2 \%)$ & $11(34.4 \%)$ \\
\hline Divorced & $2788(7.6 \%)$ & $5(7.6 \%)$ & $13623(7.5 \%)$ & $4(12.5 \%)$ \\
\hline Widowed & $413(1.1 \%)$ & $3(4.5 \%)$ & $2264(1.2 \%)$ & $1(3.1 \%)$ \\
\hline
\end{tabular}




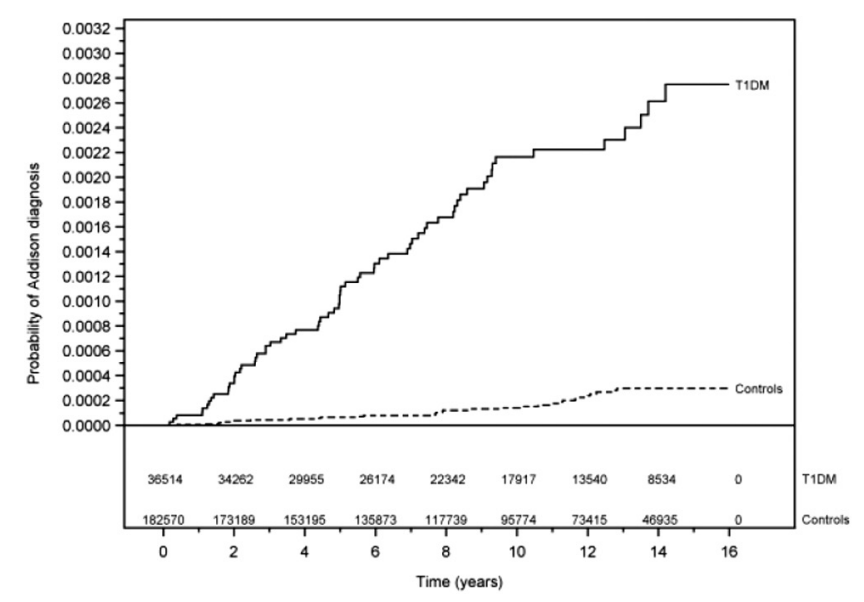

Figure 2

Time to AD diagnosis in persons with or without T1DM. Among cases with T1DM, 66 persons developed AD compared to 32 persons among control subjects (without T1DM). AD, Addison's disease; T1DM, type 1 diabetes mellitus.

\section{Prevalence of the combination of T1DM and AD}

Between 1987 and 2012, 105 persons (60 men and 45 women) were diagnosed with $\mathrm{AD}$ among 30790 alive persons at 31 December 2012 with T1DM, while 32 (16 men and 16 women) were diagnosed with AD among 153950 alive control subjects at the same date. Mean age (s.D.) at 31 December 2012 was 44.4 (14.6) years for cases and 47.6 years (14.6) for control subjects. The prevalence of AD in persons with T1DM at 31 December 2012 was estimated to be 3410 cases per million (95\% CI: 2759-4061) and the prevalence of AD in control subjects without T1DM was 208 per million (95\% CI: 136-280) (Table 3). Finally, the odds ratio of having AD among persons with T1DM, independently of which diagnosis came first, was 16.5 (95\% CI: 11.1-24.5) compared to control subjects.

\section{Discussion}

This nationwide study estimated the incidence of $\mathrm{AD}$ among persons with or without T1DM at 193 and 18 per million person-years, respectively. Persons who already had T1DM showed a more than 10-fold higher risk of developing $\mathrm{AD}$, which appeared at a younger age than persons without T1DM. Finally, the incidence of AD may have a seasonal pattern.

We found that the relative risk among persons with T1DM of developing AD was 10.8 or 16.5 higher based on incidence and prevalence estimates, respectively. The difference between the adjusted relative risk increase of developing $\mathrm{AD}$ in persons with T1DM vs control subjects and the odds ratio for $\mathrm{AD}$ in persons with T1DM vs control subjects in our studies is explained by the different definitions of these estimates, the two different time periods studied and the fact that T1DM always preceded the $\mathrm{AD}$ diagnosis in the incidence study. Besides the finding that persons with T1DM were at an increased risk of developing another autoimmune disease, i.e. AD, we found that this happened earlier in their lives compared to persons with no T1DM that develop AD. Finally, there seems to be a male predominance in persons with T1DM (1) that developed AD, which is in contrast to the female predominance of $\mathrm{AD}$ in the general population $(6,7,8,9)$.

Only two previous studies have estimated the prevalence of the combination of $\mathrm{AD}$ and T1DM on a population level. The first one, a local register-based Norwegian study, showed a prevalence of 20 per million inhabitants in Western Norway at the end of 1999 (9). Our nationwide study showed a prevalence of $\mathrm{AD}$ in persons with T1DM at 3410 cases per million at the end of 2012. It is important to clarify that that these two estimates are not comparable as the first is the prevalence of both AD and T1DM in the population and the second is the prevalence of $\mathrm{AD}$ among persons with T1DM.

Table 3 Incidence and prevalence of AD in Sweden among persons with or without T1DM. The adjusted relative risk for developing $A D$ and the odds ratio for having $A D$ in persons with T1DM compared to persons without T1DM.

\begin{tabular}{|c|c|c|c|}
\hline & Persons with T1DM & Persons without T1DM & $\begin{array}{l}\text { Risk estimate (persons with } \\
\text { vs without T1DM) }\end{array}$ \\
\hline Incidence study & $\begin{array}{l}\text { Incidence of AD (66 of } 36514): 193 \text { per } \\
\text { million person-years }(95 \% \mathrm{Cl} \text { : } \\
\text { 152-245) }\end{array}$ & $\begin{array}{l}\text { Incidence of AD (32 of } 182570) \text { : } 18 \\
\text { per million person-years (95\% Cl: } \\
13-26)\end{array}$ & $\begin{array}{l}\text { Adjusted relative risk for } \\
\text { developing AD: } 10.8 \\
(95 \% \mathrm{Cl}: 7.1-16.5)\end{array}$ \\
\hline Prevalence study & $\begin{array}{l}\text { Prevalence of AD (105 of } 30790): 3410 \\
\text { per million (95\% Cl: } 2759-4061)\end{array}$ & $\begin{array}{l}\text { Prevalence of AD (32 of } 153950): 208 \\
\text { per million }(95 \% \mathrm{Cl}: 136-280)\end{array}$ & $\begin{array}{l}\text { Odds ratio for developing } \\
\text { AD: } 16.5(95 \% \mathrm{Cl} \text { : } \\
11.1-24.5)\end{array}$ \\
\hline
\end{tabular}

AD, Addison's disease; $\mathrm{Cl}$, confidence interval; T1DM, type 1 diabetes mellitus. 


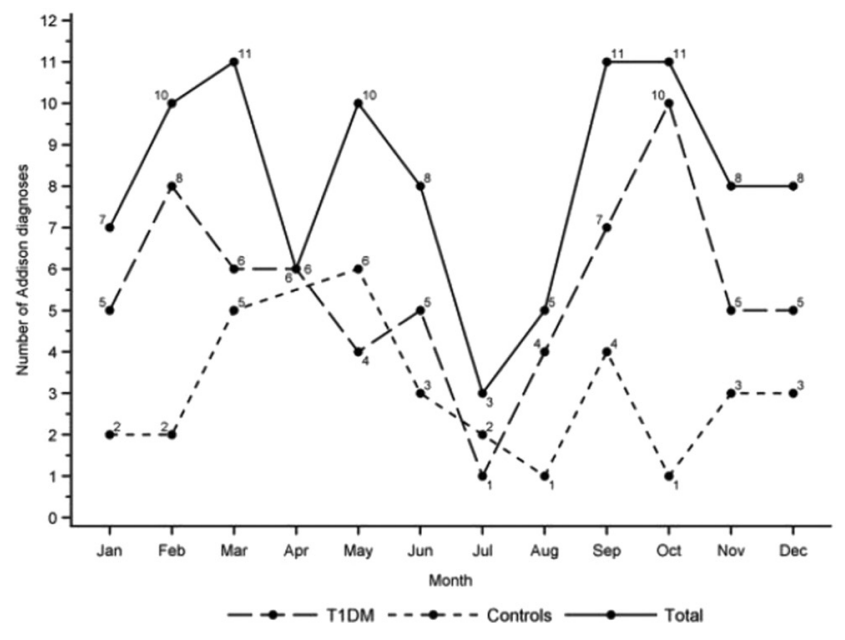

Figure 3

Seasonality for the onset $A D$ diagnosis among persons with or without T1DM, and for the whole study population.

The graph shows a cumulative number of new cases of AD for each calendar month diagnosed between 1 January 1998 and 31 December 2013. AD, Addison's disease; T1DM, type 1 diabetes mellitus.

However, the prevalence of T1DM and AD in our study was similar to that found in a US T1DM registry study at 2912 per million (75 persons had AD among 25759 T1DM persons) (2).

The prevalence of $\mathrm{AD}$ in the general population based on studies from European countries is estimated to be between 93 and 221 per million $(6,7,8,9,10,11,12)$. Based on our study design and selection of persons, we could not calculate the total prevalence of $\mathrm{AD}$; however, based on the results from the control subjects without T1DM in the general population, the prevalence of 208 per million inhabitants suggests that our estimate together with the more recent data from Iceland (12) is one of the highest reported. Both the incidence and the prevalence of T1DM are increasing globally (1) and the same trend might therefore be expected for AD (5). Our study showed an at least 2-fold higher incidence (based on 95\% CI) of $\mathrm{AD}$ compared to older studies. When interpreting these data, it should be kept in mind that our control subjects have been selected as controls to the T1DM population and are therefore not directly comparable to incidence studies based on general population.

For both T1DM and AD, there are studies suggesting a seasonality in their onset depending on either month of birth or month at diagnosis $(13,14,23)$. Month-ofbirth seasonality implies the existence of seasonal fetal or neonatal environmental factors that can predispose for the disease and month at diagnosis seasonality implies the existence of seasonal environmental factors such as infections. A study in Southeastern Sweden showed a clear variation in the onset of T1DM in children based on month at diagnosis seasonality (13). Another study showed that spring births were associated with an increased risk for T1DM in many US regions (24). The possibility that the seasonality pattern in the onset of T1DM in children depends on geographical position was suggested by a large worldwide study (14). In persons with T1DM, there are also indications that viral infections can predispose for autoimmune-mediated diseases (25). On the other hand, in $\mathrm{AD}$, a recent study demonstrated that persons born in winter had a higher risk for developing this autoimmune disease that might be explained by predisposing factors such as seasonal viral infections and vitamin D deficiency (23). In our study, we assessed month at diagnosis seasonality for the 98 persons identified with AD during a period of 16 years and observed roughly two peaks for the whole study population in the early and late winter. Data from the Public Health Agency of Sweden (Influenza in Sweden 2015-2016) show an yearly peak in laboratoryconfirmed cases of the different types of influenza and norovirus that both occur late winter. This may explain the late winter incidence peak but cannot explain the peak in early September-October. When interpreting these data, we have to take into consideration that, besides that the time between the onset and the diagnosis of AD may vary considerably, there might be a seasonal variation in the availability of health care (during summer holidays), and also that our calculations are based on limited numbers of observations over a long period of time.

Previous studies have shown an increased risk of adrenal crises among persons with both T1DM and $\mathrm{AD}(16,26,27,28)$. Adrenal crisis is potentially lifethreatening if not discovered and treated in a timely manner. Because of that, and the complex metabolic interplay between insulin and cortisol in persons with T1DM and AD, targeted information and education are needed in order to manage both diagnoses during an infection or other stressful events. The current study shows that persons with T1DM have more than 10 times higher risk of developing $\mathrm{AD}$ and that they developed $\mathrm{AD}$ at a younger age than persons without T1DM, suggesting the need of a high awareness of AD in those with T1DM and signs of incipient adrenal insufficiency. Currently, there are no guidelines that recommend screening for $\mathrm{AD}$ among persons with T1DM $(29,30,31,32,33)$.

This study has several strengths. First, we identified persons with T1DM diagnosis in NDR which have a high 
national coverage of at least $97 \%$, securing an unselected population. Second, persons with AD were identified in the Swedish National Inpatient Register, which has a national coverage of $99 \%$, using search criteria that we have previously validated (22). Finally, a detailed description of cases with T1DM at baseline was possible because of the data in NDR.

One of the limitations of the study was the absence of detailed clinical data for the matched control subjects at baseline, which would have helped in identifying associated predictive factors for this rare combination of metabolic diseases. Concerning the seasonal variation of month at diagnosis seasonality for $\mathrm{AD}$, first, we accessed the date when the diagnosis was registered, which might be different from the actual time of diagnosis, and second, we cannot exclude that the observed variation is at random because of the few observations.

In conclusion, this nationwide study showed that persons with T1DM have a more than 10-fold higher risk of developing $\mathrm{AD}$, and at a younger age than persons without T1DM. Our data may also indicate that the onset of $\mathrm{AD}$ has a seasonal variation that may be related to high burden of infections in society. The results of this study have implications for the care of persons with T1DM, strongly supporting high awareness and low threshold for biochemical evaluation of $\mathrm{AD}$ among persons with T1DM. More studies are needed to identify the associated predictive factors for this rare combination of metabolic diseases.

Declaration of interest

The authors have no conflicts of interest that could be perceived as prejudicing the impartiality of this study.

\section{Funding}

The National Diabetes Registry (NDR) receives financial support from the Swedish Association of Local Authorities and Regions and the Region Västra Götaland. The study was supported in part by the Swedish government under an ALF agreement ( $G \mathrm{~J})$. The funders of the study had no role in study design, data collection, data analysis, data interpretation or writing of the report. All authors had full access to all data in the study and shared the final responsibility for the decision to submit for publication.

\section{Author contribution statement}

All authors contributed to the design of the study and interpretation of the data. M M and A-M S acquired data. A P and S F performed the statistical analyses. D C drafted the report. All authors contributed to the writing and to the final version of the manuscript.

\section{Acknowledgements}

The authors thank Peter Todd (Tajut Ltd., Kaiapoi, New Zealand) for thirdparty writing assistance in drafting this manuscript, for which he received financial compensation from ALF funding. Some of the study results have, in part, been presented as a poster at the 19th European Congress of Endocrinology, 20-23 May 2017, in Lisbon, Portugal.

\section{References}

1 Centers for Disease Control and Prevention. National Diabetes Statistics Report: Estimates of Diabetes and its Burden in the United States, 2014. Atlanta, GA: US Department of Health and Human Services, 2014.

2 Hughes JW, Riddlesworth TD, DiMeglio LA, Miller KM, Rickels MR, McGill JB \& Network TDEC. Autoimmune diseases in children and adults with type 1 diabetes from the T1D exchange clinic registry. Journal of Clinical Endocrinology and Metabolism 2016101 4931-4937. (https://doi.org/10.1210/jc.2016-2478)

3 Betterle C, Dal Pra C, Mantero F \& Zanchetta R. Autoimmune adrenal insufficiency and autoimmune polyendocrine syndromes: autoantibodies, autoantigens, and their applicability in diagnosis and disease prediction. Endocrine Reviews 200223 327-364. (https://doi. org/10.1210/edrv.23.3.0466)

4 Boelaert K, Newby PR, Simmonds MJ, Holder RL, Carr-Smith JD, Heward JM, Manji N, Allahabadia A, Armitage M, Chatterjee KV et al. Prevalence and relative risk of other autoimmune diseases in subjects with autoimmune thyroid disease. American Journal of Medicine 2010123 183.e181-183.189. (https://doi.org/10.1016/j. amjmed.2009.06.030)

5 Bensing S, Hulting AL, Husebye ES, Kampe O \& Lovas K. MANAGEMENT OF ENDOCRINE DISEASE: Epidemiology, quality of life and complications of primary adrenal insufficiency: a review. European Journal of Endocrinology 2016175 R107-R116. (https://doi. org/10.1530/EJE-15-1242)

6 Kong MF \& Jeffcoate W. Eighty-six cases of Addison's disease. Clinical Endocrinology 199441 757-761. (https://doi. org/10.1111/j.1365-2265.1994.tb02790.x)

7 Willis AC \& Vince FP. The prevalence of Addison's disease in Coventry, UK. Postgraduate Medical Journal 199773 286-288. (https:// doi.org/10.1136/pgmj.73.859.286)

8 Laureti S, Vecchi L, Santeusanio F \& Falorni A. Is the prevalence of Addison's disease underestimated? Journal of Clinical Endocrinology and Metabolism 199984 1762. (https://doi.org/10.1210/ jcem.84.5.5677-7)

9 Lovas K \& Husebye ES. High prevalence and increasing incidence of Addison's disease in Western Norway. Clinical Endocrinology 200256 787-791. (https://doi.org/10.1046/j.1365-2265.2002.t01-1-01552.x)

10 Erichsen MM, Lovas K, Skinningsrud B, Wolff AB, Undlien DE, Svartberg J, Fougner KJ, Berg TJ, Bollerslev J, Mella B et al. Clinical, immunological, and genetic features of autoimmune primary adrenal insufficiency: observations from a Norwegian registry. Journal of Clinical Endocrinology and Metabolism 200994 4882-4890. (https:// doi.org/10.1210/jc.2009-1368)

11 Bjornsdottir S, Sundstrom A, Ludvigsson JF, Blomqvist P, Kampe O $\&$ Bensing $S$. Drug prescription patterns in patients with Addison's disease: a Swedish population-based cohort study. Journal of Clinical Endocrinology and Metabolism 201398 2009-2018. (https://doi. org/10.1210/jc.2012-3561)

12 Olafsson AS \& Sigurjonsdottir HA. Increasing prevalence of Addison disease: results from a nationwide study. Endocrine Practices 201622 30-35. (https://doi.org/10.4158/EP15754.OR)

13 Samuelsson U, Carstensen J, Lofman O \& Nordfeldt S. Seasonal variation in the diagnosis of type 1 diabetes in south-east Sweden. 
Diabetes Research and Clinical Practice 200776 75-81. (https://doi. org/10.1016/j.diabres.2006.07.023)

14 Moltchanova EV, Schreier N, Lammi N \& Karvonen M. Seasonal variation of diagnosis of Type 1 diabetes mellitus in children worldwide. Diabetic Medicine 200926 673-678. (https://doi. org/10.1111/j.1464-5491.2009.02743.x)

15 Bensing S, Brandt L, Tabaroj F, Sjoberg O, Nilsson B, Ekbom A, Blomqvist P \& Kampe O. Increased death risk and altered cancer incidence pattern in patients with isolated or combined autoimmune primary adrenocortical insufficiency. Clinical Endocrinology 200869 697-704. (https://doi.org/10.1111/j.1365-2265.2008.03340.x)

16 Chantzichristos D, Persson A, Eliasson B, Miftaraj M, Franzén S, Bergthorsdottir R, Gudbjörnsdottir S, Svensson A-M \& Johannsson G. Mortality in patients with diabetes mellitus and Addison's disease: a nationwide, matched, observational cohort study. European Journal of Endocrinology 2017176 31-39. (https://doi.org/10.1530/EJE-16-0657)

17 Dalin F, Nordling Eriksson G, Dahlqvist P, Hallgren A, Wahlberg J, Ekwall O, Soderberg S, Ronnelid J, Olcen P, Winqvist O et al. Clinical and immunological characteristics of autoimmune Addison's disease: a nationwide Swedish multicenter study. Journal of Clinical Endocrinology and Metabolism 2016102 379-389. (https://doi. org/10.1210/jc.2016-2522)

18 Rawshani A, Landin-Olsson M, Svensson AM, Nystrom L, Arnqvist HJ, Bolinder J \& Gudbjornsdottir S. The incidence of diabetes among 0-34 year olds in Sweden: new data and better methods. Diabetologia 201457 1375-1381. (https://doi.org/10.1007/s00125-014-3225-9)

19 Ludvigsson JF, Andersson E, Ekbom A, Feychting M, Kim JL, Reuterwall C, Heurgren M \& Olausson PO. External review and validation of the Swedish national inpatient register. BMC Public Health 201111 450. (https://doi.org/10.1186/1471-2458-11-450)

20 Eliasson B \& Gudbjornsdottir S. Diabetes care - improvement through measurement. Diabetes Research and Clinical Practice 2014 106 (Supplement 2) S291-S294. (https://doi.org/10.1016/S01688227(14)70732-6)

21 Olén O, Bihagen E, Rasmussen F \& Ludvigsson JF. Socioeconomic position and education in patients with coeliac disease. Digestive and Liver Disease 201244 471-476. (https://doi.org/10.1016/j. dld.2012.01.006)

22 Bergthorsdottir R, Leonsson-Zachrisson M, Oden A \& Johannsson G. Premature mortality in patients with Addison's disease: a populationbased study. Journal of Clinical Endocrinology and Metabolism 200691 4849-4853. (https://doi.org/10.1210/jc.2006-0076)

23 Pazderska A, Fichna M, Mitchell AL, Napier CM, Gan E, Ruchala M, Santibanez-Koref M \& Pearce SH. Impact of month of birth on the risk of development of autoimmune Addison's disease. Journal of Clinical Endocrinology and Metabolism 2016101 4214-4218. (https:// doi.org/10.1210/jc.2016-2392)
24 Kahn HS, Morgan TM, Case LD, Dabelea D, Mayer-Davis EJ, Lawrence JM, Marcovina SM, Imperatore G \& SEARCH for Diabetes in Youth Study Group. Association of type 1 diabetes with month of birth among U.S. youth: the SEARCH for Diabetes in Youth Study. Diabetes Care 200932 2010-2015. (https://doi.org/10.2337/dc090891)

25 Dahlquist G, Frisk G, Ivarsson SA, Svanberg L, Forsgren M \& Diderholm H. Indications that maternal coxsackie B virus infection during pregnancy is a risk factor for childhood-onset IDDM. Diabetologia 199538 1371-1373. (https://doi.org/10.1007/ BF00401772)

26 Meyer G, Badenhoop K \& Linder R. Addison's disease with polyglandular autoimmunity carries a more than 2.5 -fold risk for adrenal crises: German Health insurance data 2010-2013. Clinical Endocrinology 201685 347-353. (https://doi.org/10.1111/cen.13043)

27 Erichsen MM, Lovas K, Fougner KJ, Svartberg J, Hauge ER, Bollerslev J, Berg JP, Mella B \& Husebye ES. Normal overall mortality rate in Addison's disease, but young patients are at risk of premature death. European Journal of Endocrinology 2009160 233-237. (https:// doi.org/10.1530/EJE-08-0550)

28 Hahner S, Spinnler C, Fassnacht M, Burger-Stritt S, Lang K, Milovanovic D, Beuschlein F, Willenberg HS, Quinkler M \& Allolio B. High incidence of adrenal crisis in educated patients with chronic adrenal insufficiency: a prospective study. Journal of Clinical Endocrinology and Metabolism 2015100 407-416. (https://doi. org/10.1210/jc.2014-3191)

29 Brewer KW, Parziale VS \& Eisenbarth GS. Screening patients with insulin-dependent diabetes mellitus for adrenal insufficiency. New England Journal of Medicine 1997337 202. (https://doi.org/10.1056/ NEJM199707173370314)

30 Marks SD, Girgis R \& Couch RM. Screening for adrenal antibodies in children with type 1 diabetes and autoimmune thyroid disease. Diabetes Care 200326 3187-3188. (https://doi.org/10.2337/ diacare.26.11.3187)

31 Standards of medical care in diabetes - 2014. Diabetes Care 201437 (Supplement 1) S14-S80. (https://doi.org/10.2337/dc14-S014)

32 Husebye ES, Allolio B, Arlt W, Badenhoop K, Bensing S, Betterle C, Falorni A, Gan EH, Hulting A-L, Kasperlik-Zaluska A et al. Consensus statement on the diagnosis, treatment and follow-up of patients with primary adrenal insufficiency. Journal of Internal Medicine 2014275 104-115. (https://doi.org/10.1111/joim.12162)

33 Bornstein SR, Allolio B, Arlt W, Barthel A, Don-Wauchope A, Hammer GD, Husebye ES, Merke DP, Murad MH, Stratakis CA et al. Diagnosis and treatment of primary adrenal insufficiency: an Endocrine Society Clinical Practice Guideline. Journal of Clinical Endocrinology and Metabolism 2016101 364-389. (https://doi. org/10.1210/jc.2015-1710)

Received 10 September 2017

Revised version received 14 October 2017

Accepted 23 October 2017 